\title{
PENINGKATAN KUALITAS SISTEM INFORMASI AKADEMIK DAN KEUANGAN BERDASARKAN WEBQUAL 4.0 DAN ISO/IEC 25010: STUDI KASUS SEKOLAH TINGGI TEKNOLOGI INDONESIA TANJUNGPINANG
}

\author{
Dwi Nurul Huda* ${ }^{1}$, Dana Indra Sensuse $*^{2}$ \\ Magister Teknik Informatika Universitas AMIKOM Yogyakarta \\ E-mail: ${ }^{1}$ dwi.nurulhuda@yahoo.com, ${ }^{2}$ dana@cs.ui.ac.id
}

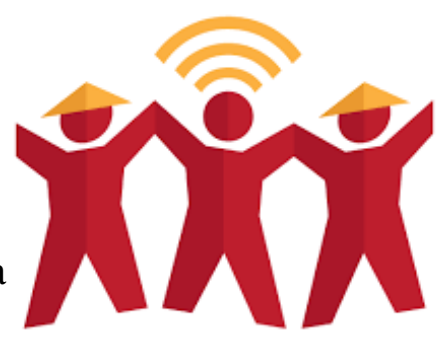

\section{ABSTRAK}

Penelitian ini berkenaan dengan evaluasi sistem informasi akademik dan keuangan pada Sekolah Tinggi Teknologi Indonesia Tanjungpinang dengan menggunakan pendekatan Webqual 4.0 dan ISO/IEC 25010.Hal ini dilakukan karena belum pernah dilakukan evaluasi mengenai kualitas sistem informasi akademik dan keuangan pada Sekolah Tinggi Teknologi Indonesia Tanjungpinang menurut persepsi pengguna. Oleh karena itu, pihak institusi belum pernah melakukan perbaikan berdasarkan persepsi pengguna. Adapun tujuan dari penelitian ini adalah untuk membuktikan bahwa penggabungan kedua buah framework Webqual 4.0 dan ISO/IEC 25010 akan menghasilkan rekomendasi yang lebih lengkap terhadap kebutuhan Sekolah Tinggi Teknologi Indonesia Tanjungpinang dibandingkan hanya menggunakan pendekatan Webqual 4.0 saja. Penelitian ini dilakukan dengan cara menyebarkan kuesioner kepada responden pengguna aplikasi. Pemilihan responden dilakukan menggunakan teknik purposive sampling sebab hanya responden yang menggunakan aplikasi saja yang dipilih. Adapun kuesioner yang disebarkan terdiri dari dua bentuk yaitu pendekatan pertama dengan Webqual 4.0 dan pendekatan kedua dengan menggunakan Webqual 4.0 yang diintegrasikan dengan ISO/IEC 25010. Pengujian hipotesis dilakukan dengan menghitung gap antara kedua kuesioner dikuatkan dengan perhitungan t-Test. Hasil penelitian ini menunjukan bahwa penggunaan metode Webqual 4.0 yang diintegrasikan dengan ISO/IEC 25010 menghasilkan penilaian kualitas perangkat lunak yang baik dibandingkan hanya menggunakan Webqual 4.0 saja. Rata-rata dimensi dalam Webqual 4.0 menghasilkan nilai 3,19(baik) sedangkan rata-rata dalam dimensi Webqual 4.0 diintegrasikan dengan ISO/IEC 25010 menghasilkan nilai 3,21(baik). Perbedaan nilai tersebut disebabkan karena indikator penilaian yang terdapat pada kuesioner menggunakan penggabungan Webqual 4.0 dan ISO/IEC lebih banyak, sehingga dapat lebih banyak memberikan rekomendasi lebih lengkap dan sesuai dengan kebutuhan organisasi. Kesimpulan penelitian ini adalah bahwa penggabungan pendekatan Webqual 4.0 dan ISO/IEC 25010 memberikan rekomendasi yang lebih lengkap bagi perbaikan sistem dibanding dengan hanya menggunakan pendekatan Webqual 4.0 saja. Adapun rekomendasi yang diberikan terhadap aplikasi berdasarkan pendekatan Webqual 4.0 dan ISO/IEC 25010 adalah perbaikan tampilan agar menarik/atraktif, perbaikan jaringan dan mengurangi kesalahan manusia ketika menggunakan aplikasi Sistem Informasi Akademik dan Keuangan.

Kata Kunci — evaluasi kualitas, website, perangkat lunak, Webqual 4.0, ISO/IEC 25010

\section{Latar Belakang}

Pemanfaatan teknologi informasi dalam dunia pendidikan terutama pada level Perguruan Tinggi merupakan suatu hal yang lazim ditemukan. Pemanfaatan teknologi informasi 
cenderung diidentikan kepada perumusan pekerjaan yang lebih cepat, akurat, efektif dan efisien baik dari segi waktu maupun biaya. Sebagai contoh adalah pada penerapan teknologi informasi tingkat Perguruan Tinggi saat penyampaian informasi disajikan melalui website resmi Perguruan Tinggi tersebut.Pemanfaatan teknologi informasi dalam Perguruan Tinggi semestinya didukung tata kelola teknologi informasi yang baik.

Fenomena mengenai tata kelola teknologi informasi yang baik berkenaan dengan kualitas perangkat lunak telah banyak dibahas oleh beberapa peneliti. Infrastruktur teknologi informasi terdiri dari fasilitas fisik, jasa dan manajemen yang mendukung seluruh sumber daya komputasi dalam suatu organisasi dengan komponen utamanya terdiri dari perangkat keras komputer, perangkat lunak komputer, fasilitas jaringan dan komunikasi, database dan bagian personalia teknologi informasi [1].

Sekolah Tinggi Teknologi Indonesia Tanjungpinang merupakan salah satu Perguruan Tinggi yang menggunakan sistem terintegrasi dengan teknologi informasi. Salah satu sistem berbasis web yang dimiliki oleh Sekolah Tinggi Teknologi Indonesia Tanjungpinang adalah sistem informasi manajemen akademik dan keuangan.Saat ini belum pernah dilakukan evaluasi terhadap kualitas perangkat lunak tersebut, sehingga institusi tidak pernah mengetahui penilaian perangkat lunak berbasis web serta belum pernah melakukan perbaikan terhadap kualitas perangkat lunak yang masih dirasa kurang berdasarkan penilainan pengguna akhir.Pendekatan yang digunakan dalam melakukan evaluasi kualitas perangkat lunak berbasis web ini menggunakan Webqual 4.0 digabungkan dengan ISO/IEC 25010.

Model ISO/IEC 25010 merupakan salah satu model yang digunakan untuk mengevaluasi kualitas perangkat lunak dan merupakan model terbaru dari model ISO/IEC sebelumnya yaitu model ISO/IEC 9126 [2]. Beberapa jurnal sebelumnya telah membahas mengenai penggunaan ISO/IEC 2510 seperti penelitian guna mengevaluasi layanan elektronik bidang pertanian pada Republik Ceko menggunakan ISO/IEC 25010 yang menghasilkan kesimpulan bahwa pemahaman pengguna layanan elektronik bidang pertanian lebih rendah dibandingkan dengan bidang industry dan jasa[3]. Sama halnya dengan ISO?IEC 25010, telah banyak jurnal yang membahas mengenai evaluasi menggunakan Webqual 4.0 yang merupakan framework yang biasa digunakan dalam penilaian kualitas website seperti contoh adalah jurnal yang membahas mengenai dampak dimensi pada Webqual dengan penilaian sikap pelanggan terhadap penggunaan e-reservasi Hotel kawasan Laut Mati dimana [4]

Berdasarkan latar belakang diatas, maka rumusan masalah dalam penelitian ini ialah “ Apakah evaluasi sistem dengan pendekatan Webqual 4.0 dan ISO/IEC 25010 akan memberikan rekomendasi/saran perbaikan yang lebih sesuai dengan kebutuhan organisasi dan yang lebih lengkap dibandingkan dengan pendekatan Webqual 4.0 saja? “

\section{LANDASAN TEORI}

\subsection{Webqual}

Pendekatan Webqual dapat menjadi satu buah pendekatan yang dapat digunakan dalam mengevaluasi kepuasan pengguna akhir terhadap website. Metode Webqual sendiri sudah mulai diperkenalkan sejak tahun 1998 oleh Barnes dan Vidgen. Metode Webqual merupakan pengembangan dari metode Servqual yang digunakan untuk mengukur kualitas jasa. Penilaian metode Webqual dilakukan dengan cara menyebarkan instrumen kepada pengguna akhir website.

Instrumen Webqual digunakan untuk mengukur kualitas suatu website berdasarkan persepsi pengguna akhir.Penelitian tentang Webqual telah dilakukan mulai websiteecommerce hingga e-governance. Menurut Barnes(2011) mengatakan bahwa :"the webquals instrument uses web site perceptions and importance to customer ratings equivalent to a two column format, an approach that we believe captures the most 
important aspects of information and interaction quality whilst keeping the number of assesment that need to be made manageable" [5]

Berdasarkan kutipan diatas dapat diketahui bahwa instrumen Webqual menggunakan pendekatan persepsi tentang website dan penilaian aspek kualitas informasi dan interaksi. Webqual telah mengalami beberapa kali perubahan disesuaikan dengan penelitian akan kebutuhan pengguna akhir. Pada Webqual 4.0 kriteria terbagi menjadi empat dimensi yaitu kebergunaan, kualitas informasi, kualitas interaksi layanan dan pendapat keseluruhan mengenai website.Namun, dimensi terakhir mengenai pendapat mengenai keseluruhan website jarang digunakan. Adapun perubahan tersebut dapat dilihat pada tabel.1 berikut :

Tabel 1 Versi webqual

\begin{tabular}{|c|l|l|}
\hline No & Jenis Versi & \multicolumn{1}{c|}{ Hasil } \\
\hline 1 & Webqual 1.0 & $\begin{array}{l}\text { Metodologi untuk instrumen menggunakan Quality } \\
\text { Function Development(QFD) dengan menitikberatkan } \\
\text { pada analisa kualitas informasi tetapi tidak kuat pada } \\
\text { interaksi layanan }\end{array}$ \\
\hline 2 & Webqual 2.0 & Menekankan pada kualitas interaksi terhadap layanan \\
\hline 3 & Webqual 3.0 & $\begin{array}{l}\text { Hasil penelitian menunjukkan bahwa analisa kualitas } \\
\text { website dikategorikan ke dalam tiga fokus area yang } \\
\text { berbeda, yaitu: Kualitas website; Kualitas informasi dan } \\
\text { Kualitas interaksi layanan. Pengujian menggunakan } \\
\text { domain online lelang }\end{array}$ \\
\hline 4 & Webqual 4.0 & $\begin{array}{l}\text { Menekanan pada pengguna dan persepsi pengguna } \\
\text { terhadap layanan bukan kepada pembuat website. } \\
\text { Membagi kedalam 4 dimensi yaitu : kualitas informasi, } \\
\text { kualitas interaksi layanan, dan kebergunaan dari interaksi } \\
\text { manusia dan komputer dan persepsi/kesan pengguna } \\
\text { akhir website. }\end{array}$ \\
\hline
\end{tabular}

\subsection{ISO/IEC 25010}

ISO (the International Organization for Standardization) dan IEC (the International Electrotechnical Commission) merupakan suatu organisasi dan komisi yang membentuk suatu sistem standarisasi yang berlaku untuk digunakan untuk seluruh dunia. ISO/IEC 25010 merupakan bagian dari standarisasi SQuaRE (Systems and software Quality Requirements and Evaluation).

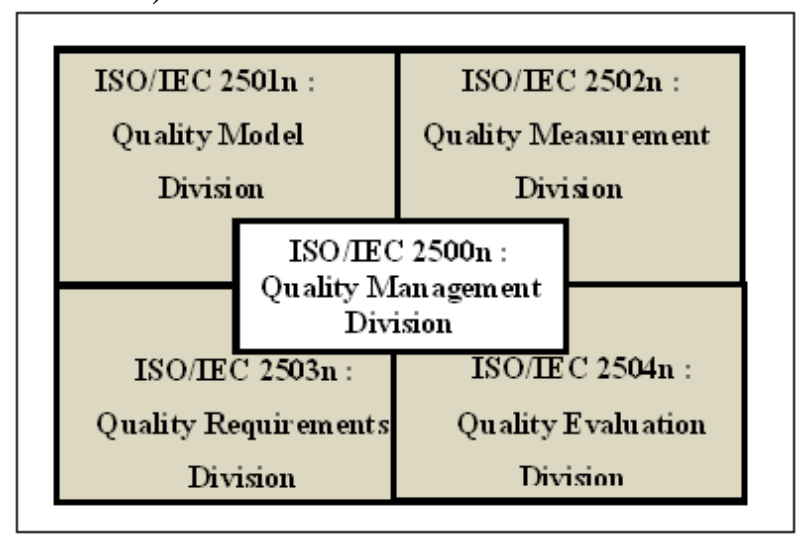

Gambar 1 Standarisasi Internasional SquaRE (iso25000.com)

Standarisasi SQuaRE yang terdiri dari beberapa divisi, yaitu : 
a. Divisi Manajemen Mutu (ISO / IEC 2500n), merupakan standar internasional yang menyediakan model umum dalam SquaRE yang selanjutnya akan dijelaskan dibawah ini. Divisi ini memberikan panduan untuk pengelolaan persyaratan, spesifikasi dan evaluasi kualitas produk perangkat lunak

b. Divisi Model Kualitas (ISO / IEC 2501n), merupakan standar internasional yang menyediakan panduan model kualitas secara rinci bagi sistem komputer dan perangkat lunak.

c. Divisi Pengukuran Kualitas (ISO / IEC 2502n)), merupakan standar internasional yang berisi panduan pengukuran kualitas perangkat lunak

d. Divisi Persyaratan Kualitas (ISO / IEC 2503n), ), divisi ini membantu menentukan kualitas dari berdasarkan model dan ukuran kualitas kebutuhan perangkat lunak

e. Divisi Evaluasi Kualitas (ISO / IEC 2504n), divisi ini memberikan persyaratan, rekomendasi, dan panduan untuk melakukan penilaian perangkat lunak [6]

ISO/IEC 25010 merupakan standarisasi baru yang dikeluarkan menggantikan standar sebelumnya yaitu ISO/IEC 9126, sehingga penelitian yang membahas mengenai metode ISO/IEC 25010 masih relatif sedikit jika dibandingkan dengan metode ISO/IEC 9126. Pada ISO sebelumnya, yaitu ISO/IEC 9126 terdapat 6 karakteristik yaitu functionality, reliability, usability, efficiency, maintaibability dan portability sedangkan ISO/IEC 25010 memiliki 13 karakteristik, yaitu effectiveness, efficiency, satisfaction, freedom for risk, context coverage, functional suitability, compability, reliability, mainability, performance efficiency, security, usability dan portability dan masing-masing karakteristik tersebut memiliki lagi subkarakteristik masing-masing. Perbedaannya adalah pada metode ISO/IEC 9126 terdapat subkarakteristik yang kini diubah menjadi karakteristik pada ISO/IEC 25010.

\section{METODE PENELITIAN}

Adapun metode penelitian yang dilakukan ialah sebagai berikut :

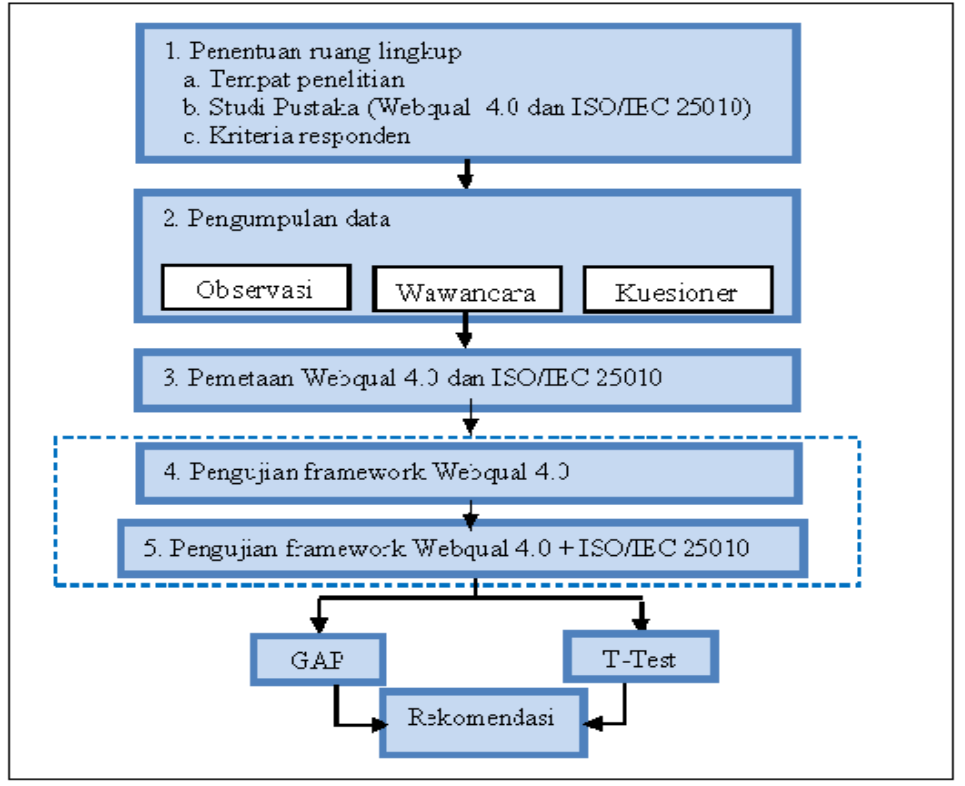

Gambar 2 Metode Penelitian

Berikut merupakan penjelasan dari gambar diatas :

Tahap 1 :Penentuan ruang lingkup dilakukan dengan melakukan kajian pembahasan pada sistem informasi akademik dan keuangan dengan mengambil studi kasus Sekolah Tinggi 
Teknologi Indonesia Tanjungpinang. Adapun pemilihan responden di ambil dengan teknik purposive sampling

Tahap 2 : Pengumpulan data dilakukan dengan menggunakan wawancara, observasi, kuesioner serta studi literatur. Observasi dilakukan dengan datang langsungpada Sekolah tinggi Teknologi Indonesia Tanjungpinang dimana Sistem informasi akademik dan keuangan berjalan, wawancara dengan para pemangku kepentingan serta melakukan penyebaran kuesioner. Adapun penyebaran kuesioner terdiri dari dua macam, yaitu pertama kuesioner menggunakan metode Webqual 4.0 dan yang kedua merupakan kuesioner menggunakan metode Webqual 4.0 di integrasikan dengan ISO/IEC 25010.

Tahap 3 : Melakukan pemetaan terhadap framework Webqual 4.0 dan ISO/IEC 25010 dengan mengambil fokus kepada pengguna sistem.

Tahap 4 : Melakukan pengujian kualitas perangkat lunak Sistem Informasi Akademik dan keuangan berbasis web dengan menyebarkan kuesioner yang berisi pertanyaan seputar kualitas web sesuai dengan dimensi yang terdapat dalam metode Webqual 4.0

Tahap 5 : Melakukan pengujian kualitas perangkat lunak Sistem Informasi Akademik dan keuangan berbasis web dengan menyebarkan kuesioner yang berisi pertanyaan seputar kualitas web sesuai dengan dimensi yang terdapat dalam metode Webqual 4.0 dan penggabungan dengan ISO/IEC 25010

Tahap 6 : Melakukan analisis data dengan mencari nilai rata-rata tiap dimensi pada pertanyaan yang terdapat dalam kuesioner dan nilai gap antara kedua kuesioner tersebut (kuesioner dengan menggunakan Webqual 4.0 dan kuesioner yang menggunakan Webqual 4.0 serta digabung dengan ISO/IEC 25010) dan dilakukan pula uji statistik menggunakan tTest untuk mengetahui apakah uji kualitas menggunakan penggabungan Webqual 4.0 dan ISO/IEC memberikan rekomendasi yang lebih lengkap dibandingkan hanya menggunakan Webqual 4.0 saja. Berdasarkan hasil pencarian nilai gap dan uji statistik menggunakan uji tTest akan di peroleh hasil untuk tahap rekomendasi yang dapat dilakukan untuk perbaikan kualitas perangkat lunak.

\section{ANALISIS DAN PEMBAHASAN}

\subsection{Pemetaan Webqual 4.0 dan ISO/IEC 25010}

Evaluasi perangkat lunak berbasis web pada penelitian ini menggunakanframework Webqual 4.0 dan ISO/IEC 25010. Adapun fokus yang diambil pada ISO/IEC 25010 hanya sebatas pengguna saja.Hal ini disebabkan karena pada Webqual 4.0 penilaian mengenai kualitas website dinilai berdasarkan persepsi pengguna akhir. Adapun gambar pemetaan antara Webqual 4.0 dan ISO/IEC 25010 dapat dilihat pada gambar berikut :

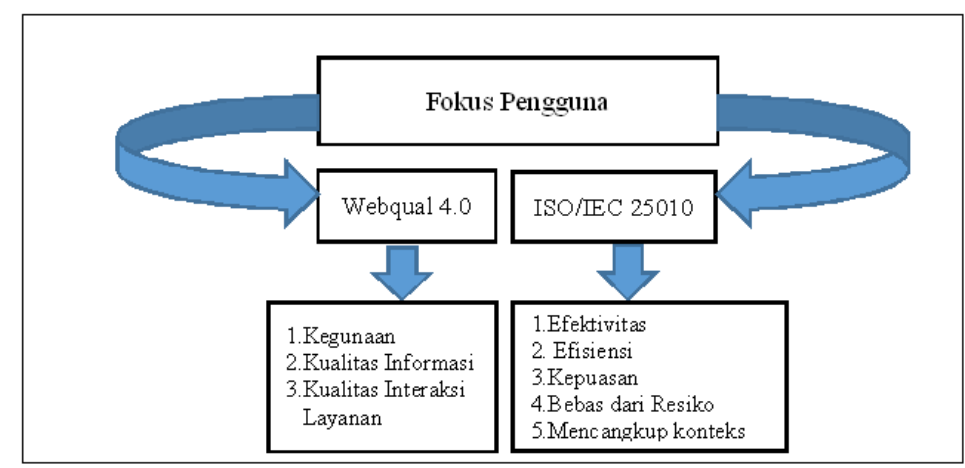

Gambar 3 Pemetaan Webqual dan ISO/IEC 25010 berdasarkan pengguna

Berdasarkan gambar.3 diatas dapat dilihat bahwa framework penilaian kualitas perangkat lunak menggunakan Webqual 4.0 dan ISO/IEC 25010 mengambil satu fokus kepada pengguna. Pemetaan dilakukan dengan mengambil seluruh dimensi yang terdapat 
pada Webqual 4.0 mencangkup dimensi kegunaan, kualitas informasi, kualitas interaksi layanan serta dimensi yang terdapat dalam ISO/IEC 25010 yang mencangkup efektivitas, efisiensi, kepuasan bebas dari risiko dan cangkupan keseluruhan. Adapun kuesioner yang dibentuk berdasarkan pemetaan tersebut dapat disajikan sebagai berikut :

Tabel 2 Kuesioner menggunakan metode WebQual 4.0 dan ISO/IEC 25010

\begin{tabular}{|c|c|c|c|c|}
\hline No & Pertanyaan/Pernyataan & & CIHAI & \\
\hline 1 & $\begin{array}{l}\text { KEGUNAAN } \\
\text { Tujuan : Mengetahui persepsi pengguna akhir } \\
\text { berdasarkan dimensi kegunaan dari website Sistem } \\
\text { Informasi Akademik dan Keuangan }\end{array}$ & SS & TS & STS \\
\hline 1.1 & $\begin{array}{l}\text { Ketika menemukan website Sistem Informasi Akademik } \\
\text { dan Keuangan, anda merasa mudah untuk belajar } \\
\text { mengoperasikan website tersebut }\end{array}$ & & & \\
\hline 1.2 & $\begin{array}{l}\text { Proses interaksi website Sistem Informasi Akademik } \\
\text { dan Keuangan jelas dan mudah dimengerti }\end{array}$ & & & \\
\hline 1.3 & $\begin{array}{l}\text { Website Sistem Informasi Akademik dan Keuangan } \\
\text { mudah untuk di navigasi/jelajahi }\end{array}$ & & & \\
\hline 1.4 & $\begin{array}{l}\text { Website Sistem Informasi Akademik dan Keuangan } \\
\text { mudah untuk digunakan }\end{array}$ & & & \\
\hline 1.5 & $\begin{array}{l}\text { Website Sistem Informasi Akademik dan Keuangan } \\
\text { memiliki tampilan yang atraktif/menarik }\end{array}$ & & & \\
\hline 1.6 & $\begin{array}{l}\text { Desain pada tampilan website Sistem Informasi } \\
\text { Akademik dan Keuangan sesuai dengan tipe website } \\
\text { untuk layanan informasi Akademik dan keuangan }\end{array}$ & & & \\
\hline 1.7 & $\begin{array}{l}\text { Website Sistem Informasi Akademik dan Keuangan } \\
\text { terlihat berkompeten }\end{array}$ & & & \\
\hline 1.8 & $\begin{array}{l}\text { Website Sistem Informasi Akademik dan Keuangan } \\
\text { dapat menciptakan pengalaman positif bagi yang } \\
\text { menggunakannya }\end{array}$ & & & \\
\hline 2 & $\begin{array}{l}\text { KUALITAS INFORMASI } \\
\text { Tujuan : Mengetahui persepsi pengguna akhir } \\
\text { berdasarkan dimensi kualitas informasi dari website } \\
\text { Sistem Informasi Akademik dan Keuangan }\end{array}$ & SS & TS & STS \\
\hline 2.1 & $\begin{array}{l}\text { Website Sistem Informasi Akademik dan Keuangan } \\
\text { menyajikan informasi yang akurat }\end{array}$ & & & \\
\hline 2.2 & $\begin{array}{l}\text { Website Sistem Informasi Akademik dan Keuangan } \\
\text { menyajikan informasi yang terpercaya }\end{array}$ & & & \\
\hline 2.3 & $\begin{array}{l}\text { Website Sistem Informasi Akademik dan Keuangan } \\
\text { menyajikan informasi yang tepat waktu }\end{array}$ & & & \\
\hline 2.4 & $\begin{array}{l}\text { Website Sistem Informasi Akademik dan Keuangan } \\
\text { menyajikan informasi yang relevan }\end{array}$ & & & \\
\hline 2.5 & $\begin{array}{l}\text { Website Sistem Informasi Akademik dan Keuangan } \\
\text { menyajikan informasi yang mudah dipahami }\end{array}$ & & & \\
\hline 2.6 & $\begin{array}{l}\text { Website Sistem Informasi Akademik dan Keuangan } \\
\text { menyajikan informasi yang terperinci/penyajian } \\
\text { informasi secara detail }\end{array}$ & & & \\
\hline 2.7 & $\begin{array}{l}\text { Website Sistem Informasi Akademik dan Keuangan } \\
\text { menyajikan informasi dengan format yang tepat }\end{array}$ & & & \\
\hline
\end{tabular}




\begin{tabular}{|c|c|c|c|c|}
\hline 3 & $\begin{array}{l}\text { KUALITAS INTERAKSI } \\
\text { Tujuan : Mengetahui persepsi pengguna akhir } \\
\text { berdasarkan dimensi kualitas interaksi dari website } \\
\text { Sistem Informasi Akademik dan Keuangan }\end{array}$ & SS & TS & STS \\
\hline 3.1 & $\begin{array}{l}\text { Website Sistem Informasi Akademik dan Keuangan } \\
\text { memiliki reputasi yang baik }\end{array}$ & & & \\
\hline 3.2 & $\begin{array}{l}\text { Website Sistem Informasi Akademik dan Keuangan } \\
\text { memberikan rasa aman dalam menyampaikan informasi } \\
\text { pribadi }\end{array}$ & & & \\
\hline 3.3 & $\begin{array}{l}\text { Website Sistem Informasi Akademik dan Keuangan } \\
\text { mampu memberikan rasa personalisasi web (respon dari } \\
\text { pengunjung web dari informasi yang disajikan) }\end{array}$ & & & \\
\hline 3.4 & $\begin{array}{l}\text { Website Sistem Informasi Akademik dan Keuangan } \\
\text { memberikan kemudahan dalam berkomunikasi dengan } \\
\text { bagian lain berdasarkan pengguna yang terdapat dalam } \\
\text { hak akses }\end{array}$ & & & \\
\hline 3.5 & $\begin{array}{l}\text { Website Sistem Informasi Akademik dan Keuangan } \\
\text { bahwa layanan informasi yang disampaikan sesuai } \\
\text { dengan kenyataan }\end{array}$ & & & \\
\hline 4 & $\begin{array}{l}\text { FEKTIFITAS DAN EFISIENSI } \\
\text { Tujuan : Mengetahui kemampuan perangkat lunak } \\
\text { dalam akurasi dan kelengkapan untuk mencapai } \\
\text { tujuan pengguna serta penggunaan sumber daya }\end{array}$ & SS & TS & STS \\
\hline 4.1 & $\begin{array}{l}\text { Website Sistem Informasi Akademik dan Keuangan } \\
\text { memiliki waktu yang cepat ketika diakses }\end{array}$ & & & \\
\hline 4.2 & $\begin{array}{l}\text { Proses penginputan data pada Website Sistem Informasi } \\
\text { Akademik dan Keuangan cepat }\end{array}$ & & & \\
\hline 4.3 & $\begin{array}{l}\text { Website Sistem Informasi Akademik dan Keuangan } \\
\text { mampu menyajikan laporan yang dibutuhkan dalam } \\
\text { waktu yang cepat }\end{array}$ & & & \\
\hline 4.4 & $\begin{array}{l}\text { Website Sistem Informasi Akademik dan Keuangan } \\
\text { memberikan respon yang cepat ketika pengguna } \\
\text { meminta suatu informasi }\end{array}$ & & & \\
\hline 5 & $\begin{array}{l}\text { KEPUASAAN } \\
\text { Tujuan : Mengetahui kemampuan perangkat lunak } \\
\text { dalam meringankan potensi risiko pada ekonomi, } \\
\text { kehidupan manusia, kesehatan atau faktor } \\
\text { lingkungan sekitar }\end{array}$ & SS & TS & STS \\
\hline 5.1 & $\begin{array}{l}\text { Website Sistem Informasi Akademik dan Keuangan } \\
\text { tidak pernah mengalami permasalahan jaringan seperti } \\
\text { not responding }\end{array}$ & & & \\
\hline 5.2 & $\begin{array}{l}\text { Pengguna merasa puas sebab data yang telah tersimpan } \\
\text { dalam Website Sistem Informasi Akademik dan } \\
\text { Keuangan tidak akan hilang walaupun perangkat anda } \\
\text { rusak dan mati listrik }\end{array}$ & & & \\
\hline 5.3 & $\begin{array}{l}\text { Website Sistem Informasi Akademik dan Keuangan } \\
\text { menampilkan informasi yang jelas walaupun } \\
\text { menggunakan perangkat dengan screen yang relatife } \\
\text { kecil (seperti pengaksesan website menggunakan }\end{array}$ & & & \\
\hline
\end{tabular}




\begin{tabular}{|c|c|c|c|c|}
\hline & handphone) & & & \\
\hline 5.4 & $\begin{array}{l}\text { Pengguna merasa puas dengan penanganan yang cepat } \\
\text { terhadap Website Sistem Informasi Akademik dan } \\
\text { Keuangan jika terjadi permasalahan didalamnya }\end{array}$ & & & \\
\hline 5.5 & $\begin{array}{l}\text { Pengguna merasa puas dengan tindakan yang diambil } \\
\text { oleh IT Support berhubungan dengan penanganan } \\
\text { permasalahan Website Sistem Informasi Akademik dan } \\
\text { Keuangan }\end{array}$ & & & \\
\hline 5.6 & $\begin{array}{l}\text { Pengguna merasa puas dengan kelengkapan informasi } \\
\text { yang disajikan dalam Website Sistem Informasi } \\
\text { Akademik dan Keuangan }\end{array}$ & & & \\
\hline 5.7 & $\begin{array}{l}\text { Pengguna sering memanfaatkan layanan yang tersedia } \\
\text { dalam Website Sistem Informasi Akademik dan } \\
\text { Keuangan }\end{array}$ & & & \\
\hline 5.8 & $\begin{array}{l}\text { Pengguna Website Sistem Informasi Akademik dan } \\
\text { Keuangan memperoleh skill baru ketika menggunakan } \\
\text { website tersebut }\end{array}$ & & & \\
\hline 5.9 & $\begin{array}{l}\text { Pengguna Website Sistem Informasi Akademik dan } \\
\text { Keuangan memperoleh pengalaman baru ketika } \\
\text { mengakses website tersebut }\end{array}$ & & & \\
\hline 6 & $\begin{array}{l}\text { BEBAS DARI RISIKO } \\
\text { Tujuan : Mengetahui kemampuan perangkat lunak } \\
\text { dalam meringankan potensi risiko pada ekonomi, } \\
\text { kehidupan manusia, kesehatan/faktor lingkungan } \\
\text { sekitar }\end{array}$ & SS & TS & STS \\
\hline 6.1 & $\begin{array}{l}\text { Website Sistem Informasi Akademik dan Keuangan } \\
\text { tidak mengalami error termasuk ketika jaringan sedang } \\
\text { down }\end{array}$ & & & \\
\hline 6.2 & $\begin{array}{l}\text { Website Sistem Informasi Akademik dan Keuangan } \\
\text { menyediakan fasilitas panduan penggunaan sistem, } \\
\text { sehingga risiko human error tidak terjadi }\end{array}$ & & & \\
\hline 6.3 & $\begin{array}{l}\text { Penggunaan Website Sistem Informasi Akademik dan } \\
\text { Keuangan mengurangi biaya operasional (seperti } \\
\text { melakukan print KRS, KHS, transkrip nilai dan lainnya) }\end{array}$ & & & \\
\hline 6.4 & $\begin{array}{l}\text { Website Sistem Informasi Akademik dan Keuangan } \\
\text { memudahkan pengguna dalam memperoleh informasi } \\
\text { sebab tidak usah bertemu bagian yang berkewanangan } \\
\text { langsung untuk memperoleh informasi tersebut }\end{array}$ & & & \\
\hline 7 & $\begin{array}{l}\text { MENCANGKUP KESELURUHAN } \\
\text { Tujuan : Mengetahui Kemampuan perangkat lunak } \\
\text { untuk dijalankan lebih efektif, efisien, bebas dari } \\
\text { berbagai risiko, serta kepuasan pengguna ketika } \\
\text { dijalankan dalam konteks tertentu }\end{array}$ & SS & TS & STS \\
\hline 7.1 & $\begin{array}{l}\text { Website Sistem Informasi Akademik dan Keuangan } \\
\text { memiliki sifat fleksibel }\end{array}$ & & & \\
\hline
\end{tabular}




\subsection{PENGOLAHAN DATA}

Setelah kuesioner disebarkan tahap selanjutnya adalah melakukan pengolahan data terhadap data kuesioner yang telah diperoleh tersebut.Sebelumnya dari pertanyaan kuesioner terdapat 4 pilihan jawaban kriteria penilaian. Adapun kriteria penilaian [7] yang dimaksud adalah sebagai berikut :

Tabel 3 Kriteria penilaian

\begin{tabular}{|c|c|l|c|}
\hline No & Simbol & \multicolumn{1}{|c|}{ Kriteria penilaian } & Skor \\
\hline 1 & SS & Sangat Setuju/Sangat Baik & 4 \\
\hline 2 & S & Setuju / Baik & 3 \\
\hline 3 & TS & Tidak Setuju / Tidak Baik & 2 \\
\hline 4 & STS & $\begin{array}{l}\text { Sangat Tidak Setuju/ Sangat Tidak } \\
\text { Baik }\end{array}$ & 1 \\
\hline
\end{tabular}

Sumber : Riduwan (2009)

Selanjutnya pengolahan data dilakukan dengan mengubah hasil jawaban dari kriteria penilaian kedalam bentuk rentang skala.Berdasarkan perhitungan mengenai rentang skala (RS)[8], maka dapat diperoleh tabel interval skor sebagai berikut :

Tabel 4 Interpretasi skor rata-rata

\begin{tabular}{|c|l|}
\hline Interval & \multicolumn{1}{|c|}{ Kriteria } \\
\hline $3,25-4,00$ & Sangat Setuju/Sangat Baik \\
\hline $2,50-3,24$ & Setuju / Baik \\
\hline $1,75-2,49$ & Tidak Setuju / Tidak Baik \\
\hline $1,00-1,74$ & $\begin{array}{l}\text { Sangat Tidak Setuju/ Sangat Tidak } \\
\text { Baik }\end{array}$ \\
\hline
\end{tabular}

Berdasarkan hasil rekapitulasi kuesioner maka dapat disajikan hasil dari perolehan dua buah kuesioner sebagai berikut:

Tabel 5 Penilaian dua buah kuesioner

\begin{tabular}{|r|l|r|r|r|}
\hline No & \multicolumn{1}{|c|}{ Dimensi } & $\begin{array}{c}\text { Rata- } \\
\text { Rata } \\
\text { Webqual }\end{array}$ & $\begin{array}{c}\text { Rata-rata } \\
\text { Webqual + } \\
\text { ISO/IEC } \\
\mathbf{2 5 0 1 0}\end{array}$ & GAP \\
\hline 1 & Usability & 3,17 & 3,24 & 0,07 \\
\hline 2 & $\begin{array}{l}\text { Kualitas } \\
\text { Informasi }\end{array}$ & 3,2 & 3,24 & 0,03 \\
\hline 3 & Kualitas Interaksi & 3,2 & 3,31 & 0,11 \\
\hline 4 & $\begin{array}{l}\text { Efektifitas dan } \\
\text { Efisiensi }\end{array}$ & & 3,18 & 3,18 \\
\hline 5 & Satisfaction & & 3,16 & 3,16 \\
\hline 6 & Freedom For Risk & & 3,14 & 3,14 \\
\hline 7 & Context Coverage & & 3,2 & 3,2 \\
\hline & Rata-Rata & 3,19 & 3,21 & 0,02 \\
\hline
\end{tabular}

\subsection{Analisis Data}

Hasil rata-rata pengukuran kuesioner menggunakan Webqual 4.0 dengan mengacu pada tabel 5 akan menghasilkan nilai kualitas perangkat lunak berbasis web sebesar 3,19 dan jika melihat pada tabel 4, maka pengukuran kualitas perangkat lunak berbasis web menggunakan Webqual 4.0 berada pada tingkat baik sedangkan untuk kuesioner yang menggunakan metode 
Webqual 4.0 digabungkan dengan ISO/IEC 25010 memperoleh perolehan nilai sebesar 3,21 dan jika mengacu pada tabel 4 maka kualitas perangkat lunak berbasis web berada pada tingkat baik pula, sehingga pengukuran kuesioner menggunakan Webqual 4.0 dan penggabungan Webqual 4.0 dengan ISO/IEC 25010 secara kualitas website Sistem Informasi Manajemen Akademik dan Keuangan tidak terdapat perbedaan penilaian sebab keduanya sama-sama berada pada level baik walaupun keduanya tidak menghasilkan hasil nilai rata-rata kuesioner yang sama sebab masih terdapat gap antara keduanya.

Berdasarkan hasil tabel 5 pula disajikan nilai gap antara rata-rata pengukuran menggunakan Webqual 4.0 dan metode Webqual 4.0 berintegrasi dengan ISO/IEC 25010 yang tidak signifikan sebab menghasilkan nilai gap 0,02. Berdasarkan nilai gap tersebut dapat diambil kesimpulan bahwa pengujian kedua kuesioner tersebut walaupun memiliki hasil penilaian yang sama pada level baik, namun tetap berbeda. Apabila dilihat dari segi kelengkapan rekomendasi yang diberikan guna perbaikan kualitas perangkat lunak Sistem Informasi Manajemen Akademik dan Keuangan lebih baik menggunakan penggabungan Webqual 4.0 dan ISO/IEC 25010 karena dimensi yang dijadikan indikator penilaian lebih banyak dibanding hanya menggunakan Webqual 4.0 saja (lihat pada gambar 3). Hal ini diperkuat dengan melakukan perhitungan menggunakan T-Test.

\begin{tabular}{|c|c|c|c|c|c|c|c|c|c|}
\hline & \multicolumn{8}{|c|}{ Paired Samples Test } \\
\hline & & \multirow[b]{2}{*}{ Mean } & \multirow[b]{2}{*}{ Std.Deviation Std } & \multirow[b]{2}{*}{ Error Mean } & \multicolumn{5}{|c|}{$95 \%$ Confidence Interval of the Difference } \\
\hline & & & & & Lower & Upper & $\mathrm{t}$ & $\mathrm{df}$ & Sig.(2-tailed) \\
\hline Pair 1 & Webqual-Webqual_ISO & -58.267 & 15.254 & 2.785 & -63.963 & -52.571 & -20.922 & 29 & 0.000 \\
\hline
\end{tabular}

Gambar 4 Pengujian statistik menggunakan T-Test

Berdasarkan hasil uji T-Test diperoleh hasil penggabungan dua buah pendekatan Webqual dan ISO/IEC 25010 akan menghasilkan rekomendasi/saran yang lebih lengkap dibandingkan hanya menggunakan metode Webqual 4.0 saja berhubungan dengan perbaikan kualitas perangkat lunak berbasis Web sebab H0 ditolak dan H1 diterima(probalilitas < 0.05 , maka H0 ditolak).

\subsection{Panduan Perbaikan}

Berdasarkan nilai rata-rata setiap pertanyaan pada kuesioner yang disebarkan terdapat beberapa pertanyaan pada dimensi kegunaan, kepuasan dan bebas dari risiko yang masih perlu dilakukan perbaikan, sebab nilai yang diperoleh masih kurang dari 3 walaupun telah berada pada level baik.berikut rekomendasi yang diberikan guna perbaikan kualitas perangkat lunak berbasis web :

Tabel 6 Rekomendasi

\begin{tabular}{|l|l|l|}
\hline No & \multicolumn{1}{|c|}{ Dimensi } & \multicolumn{1}{|c|}{ Saran Perbaikan } \\
\hline 1 & $\begin{array}{l}\text { Usability pada } \\
\text { bagiantampilan } \\
\text { yang } \\
\text { menarik/atraktif }\end{array}$ & $\begin{array}{l}\text { Membuat blueprint IT , berisi spesifikasi dari } \\
\text { komponen serta konten, fungsionalitas, hubungan, } \\
\text { konektivitas, dan interaksi } \\
\text { Melakukan perbaikan terhadap tampilan website melalui } \\
\text { perubahan tampilan website supaya lebih menarik/atraktif } \\
\text { dengan mempertimbangkan penggunaan prinsip usability } \\
\text { yang terdapat dalam interaksi manusia dan komputer } \\
\text { b. Melakukan pengujian/penilaian terhadap tampilan } \\
\text { baru kepada stakeholder agar diketahui keinginan dari } \\
\text { stakeholder }\end{array}$ \\
\hline 2 & $\begin{array}{l}\text { Kepuasan } \\
\text { mengenai } \\
\text { permasalahan } \\
\text { jaringan seperti } \\
\text { not responding }\end{array}$ & $\begin{array}{l}\text { Memponen perangkat server sesuai dengan kebutuhan } \\
\text { b. Perlunya pemeriksaan/pengontrolan oleh bagian } \\
\text { pusat komputer terhadap perangkat yang digunakan sebagai } \\
\text { perangkat pendukung server termasuk mengganti perangkat }\end{array}$ \\
\hline
\end{tabular}




\begin{tabular}{|c|c|c|}
\hline & & $\begin{array}{l}\text { lama yang sudah using } \\
\text { c. Penyediaan UPS agar ketika listrik mati, server } \\
\text { tidak ikut mati } \\
\text { d. Melakukan upgrade terhadap hardisk dan RAM } \\
\text { e. Melakukan restart server agar server tidak berat } \\
\text { ketika akan diakses }\end{array}$ \\
\hline 3 & $\begin{array}{lr}\text { Bebas } & \text { dari } \\
\text { risiko } & \text { seperti } \\
\text { aplikasi } & \text { error } \\
\text { ketika jaringan } \\
\text { sedang down }\end{array}$ & $\begin{array}{l}\text { a. Membuat blueprint IT , mengenai spesifikasi dari } \\
\text { komponen perangkat server sesuai dengan kebutuhan } \\
\text { b. Penyediaan UPS agar ketika listrik padam, server } \\
\text { tidak ikut mati karena apabila listrik padam dan server mati } \\
\text { dapat mengakibatkan jaringan down dan aplikasi } \\
\text { mengalami error } \\
\text { Perlunya pemeriksaan/pengontrolan oleh bagian pusat } \\
\text { komputer terhadap perangkat yang digunakan sebagai } \\
\text { perangkat pendukung server termasuk mengganti perangkat } \\
\text { lama yang sudah usang } \\
\text { c. Melakukan upgrade terhadap hardisk dan RAM } \\
\text { d. Melakukan restart server agar server tidak berat } \\
\text { ketika akan diakses } \\
\text { e. Melakukan restart server agar server tidak berat } \\
\text { ketika akan diakses }\end{array}$ \\
\hline 4 & $\begin{array}{l}\text { Bebas dari } \\
\text { risiko seperti } \\
\text { mengurangi } \\
\text { terjadinya } \\
\text { human error }\end{array}$ & $\begin{array}{l}\text { 1. Membuat menu help pada aplikasi SIMAK } \\
\text { mengenai panduan penggunaan aplikasi berdasarkan hak } \\
\text { akses pada aplikasi SIMAK } \\
\text { 2. Membuat manual book mengenai panduan } \\
\text { penggunaan aplikasi SIMAK } \\
\text { 3. Melakukan pelatihan kepada stakeholder tentang } \\
\text { tata cara dan prosedur penggunaan aplikasi SIMAK agar } \\
\text { mengurangi terjadinya human error } \\
\text { 4. Menyediakan fasilitas chat online didalam aplikasi } \\
\text { SIMAK }\end{array}$ \\
\hline
\end{tabular}

\section{Kesimpulan}

Berdasarkan hasil analisis data sebelumnya, maka diperoleh kesimpulan sebagai berikut :

1. Hasil penilaian kuesioner bahwa website Sistem Informasi Akademik dan Keuangan Sekolah Tinggi Teknologi Indonesia Tanjungpinang menggunakan framework Webqual 4.0 menghasilkan nilai rata-rata kualitas perangkat lunak sebesar 3,19 yang berarti berada di level baik sedangkan menggunakan framework Webqual 4.0 diintegrasikan dengan ISO/IEC 25010 mencapai nilai rata-rata 3,21 yang berarti telah berada pada level baik pula. Penggunaan Webqual 4.0 dan Webqual 4.0 integrasi dengan ISO/IEC 25010 dalam melakukan penilaian kualitas perangkat lunak tidak begitu terlihat perbedaanya secara signifikan sebab menghasilkan nilai gap 0,02 dan sama-sama berada pada level baik. Hanya apabila melihat pada rekomendasi perbaikan yang lebih lengkap Webqual 4.0 kurang cocok digunakan sebab memiliki dimensi yang lebih sedikit dalam indikator penilaiannya yaitu hanya membandingkan 3 dimensi saja yaitu usability, kualitas informasi dan layanan sedangkan jika Webqual 4.0 digabungkan dengan ISO/IEC 25010 akan ada dinilai pada dimensi lain yang menjadi dimensi penilaian seperti keefektifan dan efisiensi, kepuasan, serta bebas dari risiko. 
2. Penggunaan framework Webqual 4.0 berintegrasi dengan ISO/IEC 25010 dapat menghasilkan rekomendasi yang lebih lengkap bagi perbaikan perangkat lunak Sistem Informasi Akademik dan Keuangan sebab jumlah dimensi yang menjadi indikator penilaian pada framework Webqual 4.0 berintegrasi dengan ISO/IEC 25010 lebih lengkap dibandingkan hanya menggunakan Webqual 4.0 saja

3. Penilaian website SIMAK menggunakan Webqual 4.0 berintegrasi dengan ISO/IEC 25010 menghasilkan beberapa hal yang masih perlu dilakukan perbaikan guna menghasilkan perangkat lunak yang baik. Adapun bagian yang perlu dilakukan perbaikan yaitu pada segi tampilan agar menarik/atraktif, permasalahan jaringan yang mengakibatkan SIMAK not responding atau error hingga mengurangi kesalahan manusia dalam menggunakan SIMAK

\section{SARAN}

Berdasarkan hasil penelitian diatas, maka dapat di buat beberapa saran berikut :

1. Pengukuran tingkat kualitas perangkat lunak belum pernah dilakukan sebelumnya, sehingga belum ada SOP yang mendukung mengenai target capaian kualitas perangkat lunak yang ada di Sekolah Tinggi Teknologi Indonesia Tanjungpinang. Alangkah baiknya di buat SOP mengenai target yang ingin dicapai dalam penilaian kualitas perangkat lunak SIMAK ke depan sesuai dengan hasil dari penelitian ini

2. Penilaian perangkat lunak pada penelitian ini sebatas pada persepsi pengguna akhir saja. Alangkah lebih baik apabila penilaian terhadap perangkat lunak bukan hanya menurut persepsi pengguna akhir saja tetapi berdasarkan produk dari perangkat lunak itu sendiri

\section{DAFTAR PUSTAKA}

[1]Suyanto, M., 2005, Pengantar Teknologi Informasi Untuk Bisnis, Andi, Yogyakarta

[2] Miguel, J.P.; Mauricio, D;Rodríguez, G, 2016, A Review of Software Quality Models for theEvaluation of Software Products, International Journal of Software Engineering \& Applications (IJSEA), Vol.5, No.6, November 2014, https://arxiv.org/ftp/arxiv/papers/1412/1412.2977.pdf [30 September 2016]

[3]Ulman, M.; Vostrovský, V.; Tyrychtr, J., 2016, Agricultural E-Government : Design of Quality Evaluation Method Base on ISO SquaRE Quality Model, Agris on-line Papers of Economics and Informatics, 2013, http://ageconsearch.umn.edu/bitstream/162303/2/agris_online_2013_4_ulman_vostrovsy _tyrychtr.pdf [08 Oktober 2016]

[4] Malek, A., 2016,Impact of WEBQUAL Dimensions on Customers Attitudes toward EReservation Services Adoption (ERSA) in Jordanian Hotels, European Journal of Business and ManagementISSN 2222-1905 (Paper) ISSN 2222-2839 (Online)Vol.7, No.5, 2015Teknomatika, Vol.8 No.1 Tahun 2015, 2015,http://iiste.org/Journals/index.php/EJBM/article/viewFile/20279/20642 [08Oktober 2016]

[5]Barnes;Stuart,J., 2011, Business The Strategic Implications Of Wireless Communications, Routledge, Newyork

[6]ISO/IEC 25010 : 2011, 2016, System and Software Engineering-Systems and Software Quality Requirements and Evaluation(SQuaRE) - System and software quality models, https://www.iso.org/obp/ui/\#iso:std:iso-iec:25010:ed-1:v1:en [12 Desember 2016]

[7] Riduwan, 2009, Skala Pengukuran Variabel-Variabel Penelitian, Alfabeta, Bandung

[8] Simamora, B., 2005, Analisis Multivariant Pemasaran, PT.Gramedia Pustaka Utama, Jakarta 